\title{
Erratum to: Design to doc framework: a model to support aircraft direct operating cost reduction
}

\author{
Sandro Giovanni Valeri · Luís Gonzaga Trabasso
}

Received: 29 April 2015 / Accepted: 29 April 2015 / Published online: 27 May 2015

(C) The Brazilian Society of Mechanical Sciences and Engineering 2015

Erratum to: J. Braz. Soc. Mech. Sci. Eng.

DOI 10.1007/s40430-014-0236-x

Unfortunately, in the original publication of this article the second author Professor Luís G. Trabasso was missing.

The online version of the original article can be found under doi:10.1007/s40430-014-0236-x.

S. G. Valeri $(\bowtie)$

São José dos Campos, Brazil

e-mail: sandro.valeri@embraer.com.br

L. G. Trabasso

Divisão de Engenharia Mecânica, Instituto Tecnológico de Aeronáutica, 12.228-900 São José dos Campos, SP, Brazil e-mail: gonzaga@ita.br 